\title{
Investigating the Open Access Experience of Lecturers during Their Teaching from Home
}

\author{
Heriyanto $^{*}$ Rukiyah, Lydia Christiani, Selyna Anggita, Elvy \\ Library Studies, Faculty of Humanities, Diponegoro University, Indonesia
}

\begin{abstract}
Open access has become an essential component of spreading and sharing scholarly knowledge. It has become a significant alternative to traditional publishing options. This is because scholarly works such as journal articles, that are available via open access channels, are more likely to be read by the research community. This research investigate how lecturers use open access information to during their online teaching. A qualitative approach will be employed which includes interviews with Humanities Faculty lecturers. The approach is used to explore, interpret and report on the lived experiences of lecturers and to offer insights into their use of using open access information during their teaching from home.
\end{abstract}

\section{Background of the Study}

Accessing and submitting scholarly works to subscription-based journals has been the main publishing option for academics wanting to disseminate their research endeavours. Recent advances in technology, however has changed the ways academics now publish. Open Access has emerged as another viable way for academics to publish and disseminate their scholarly works. This publication model has become an essential component of spreading and sharing scholarly knowledge [1]. Open Access offers an alternative way for the publication of research works by distributing the works freely through the Web without copyright barriers. This new way advances knowledge and science faster than by publishing in the traditional way [2]. Many studies have explored the benefits of Open Access for publishing research output, and most of these studies have revealed that Open Access publications disseminate research outputs earlier and wider [2].

Many countries have made a significant commitment to the development of Open Access sources underpinned by their approach aimed at providing better access to the outputs of government-funded research. Started in 2005 the Australian Research Council (ARC) recommending that the Australian research organisations and institutions which provide public research funding to make the research work is made publicly available. The ARC's policy then followed by the National Health and Medical Research Council (NHMRC) in 2012 that announced their policy on the dissemination of research findings. Both of ARC and the NHMRC's aim was, "to ensure that Australia contributes to global effort to facilitate sustainable open access models" [3].

* Corresponding author: heriyanto@live.undip.ac.id 
In relation to the ARC and NHMRC's open access mission, the Australian universities have started developing their digital repository before the Australian government implementing their supporting policy. The first Australian university who established digital repository was Australian National University (ANU) in 2001. By the end 2003, the repository had archived over 2,000 documents and had seen 209,401 downloads. Currently, there were 6798 documents deposited in the repository. In Australia-wide the majority of Australian universities have established their institutional repository services [4].

The publication of scholarly works through the open access channels provides an opportunity for wider dissemination and also supports the enhancement of research and scholarship. Many studies have looked at the usage of open access for academic purposes. However, to date there are no studies that discovered that Indonesian lecturers on the usage of Open Access information.

\section{Research Problem}

A growing body of research has begun to explore open access and to guide this movement of scholarly communication. This research has focussed on two main areas of enquiry: impact and user perspective. Research exploring open access from the perspective of impact has investigated how frequently articles published in open access channels are cited compared to articles published in other channels [5,6]. But citation does not necessarily explain how researchers actually use and engage with the articles they obtain via open access. Research exploring open access from the perspective of the user has tried to fill this gap. For example, studies have begun to explore research students awareness, attitude and engagement with university repositories $[7,8]$. But these studies do not explore how researchers use and relate open access information into their broader scholarly information worlds. Nor do these studies explore how materials obtained via open access channels influence the researcher's knowledge base and understandings. The research question for this study is how do lecturers experience open access during their teaching from home?

\section{Research Method}

This research looking at the phenomenon from a specific context by specific group of people, thus the researcher will employ a qualitative approach to explore how researchers within a particular context, Australian universities, experience open access during their research. Qualitative approach would be effective for a study that aims to explore and understand the meaning of an individual or group ascribes to a special context [9], and obtaining information about values, opinions and behaviour of particular populations. Another rationality to employ qualitative approach is because this current study will investigate a research problem that enquiring an exploration and understanding of the phenomenon of Humanities Faculty lecturers in experiencing open access sources. It uses words as data with the researchers making interpretations of the meaning of the data. Qualitative approach enables the researcher "to get 'under the skin' of a group or organization to find out what really happens." The participants of this study will be Humanities Faculty, Diponegoro university lecturers. The participants will be interviewed using semi-structured interview to develop a greater understanding of the lived experiences of the participants in using Open Access source. The current study is semi-structured interviews because of the flexibility in combining the formal and informal conversation. The questions are designed and structured prior the interview session, but there was also a chance for the interviewer to follow up responses given from the participant in order to keep the conversation on topic being discussed. The informal conversation that rises during the interview can be useful to anticipate any gaps for data 
collection, and to clarify different perceptions that come from participants responses. Where the purpose of the study is to explore the experiences of researchers on using the open access information, hence in order to obtain a depth and broad range of information, a planned question is considered necessary to manage the interview process [10].

The general aim of the interviews will be to develop a greater understanding of the lived experiences of the participants in using Open Access sources as part of the broader information worlds, so than the researcher will provide brief introduction to the participant about the study and the purpose of the interview.

\section{Research Significance}

It is hoped findings will creating new knowledge in the field of Open Access and information literacy for researchers to use and build upon. The research will contribute a new empirially derived understanding of lecturers use of Open Access information as part of their broaden information world. The research will also support Indonesia universities by providing an evidence based that can be used to inform the development of information literacy programs managed by university libraries thus helping to ensure the programs genuinely meet the information literacy needs of this group of lecturers. It will also provide an evidence base that can inform Indonesia universities in their approaches to supporting and enabling access to Open Access information to lecturers.

The research will for the first time, provide an empirical evidence to highlighting how researchers use and engage with information retrieved from Open Access channels as part of their overall information literacy experience. This study will provide insights into the various ways lecturers use open access information as part of their broader information worlds, and their perceptions of the major impediments and incentives for incorporating Open Access information obtained from Open Access channels into their professional practice. It is anticipated that this study will be of interest to the research domains of information literacy, library and information science, and higher education. It is expected that Indonesia university libraries will be able to use the findings from the study to inform their information literacy practitioners, for example the liason librarian, about the way researchers using Open Access sources.

\section{Literature Review}

\subsection{Research into Open Access}

A growing number of studies have begun to explore the open access phenomenon. The question of Open Access information usage was addressed in another study. Chaudhuri and Thohira [11] explored the usage patterns of open access and hybrid open access journals in selected scholarly publications. They analyzed eleven high impact science and medical journals for 2004, 2006, and 2008. Among the subjects investigated, biology, medical science and mathematics were the three highest users of open access journals. While biology and mathematics were the two subject areas that had the most significant increase of use. The study concluded that overall most of the journals have indicated increase in use over the years.

However citation count does not consider the ways in which researchers use the articles obtained via open access. Research exploring open access from the perspective of user engagement has tried to fill this gap. For example, studies have explored how research students are aware of and use their university repository [7, 8]. While providing an interesting insight into the researchers experience of open access these studies have focussed only on 
the attitudes and perceptions of lecturers, the studies have not explored open access from an information literacy perspective.

\subsection{Research into Information Literacy}

There is growing body of research exploring information literacy and researchers. Few studies about the researchers information literacy have been done in higher education context. Williamson, Vivienne, Wright \& Sullivan [12] and Green \& Macauley [13] have tried to fill this gap by exploring the research students' information literacy by looking at the way they finding and evaluating information. In these studies, information literacy was understood as the way people experience information. To be exact, this study employ Bruce's concept of information literacy [14] which attempts to explore variations in how people experience particular aspects in accessing information. However, the experience that was looking at in these studies were about search tools the participants use and what type of information the participants prefer to use (e.g electronic form). It does not explains how the participants use the information found for their study.

\section{Pilot Study}

A pilot study has been conducted by recruiting and interviewing researchers from the Humanities Faculty, Diponegoro University. It aims to refine the data collection techniques that will be used for the main study. By the end of the pilot project, the researcher was able to evaluate and develop relevant questions to ask to the participants. Moreover, it may provide conceptual clarification for the research design [15].

The preparation for the pilot including writing a recruitment email that was intended for the Humanities Faculty WhatsApp group. This is the group that used by the Humanities Faculties academics. The expectation was to get 4 researchers from Humanities Faculty who have used Open Access sources during their online teaching.

Each interviews run approximately 30-50 minutes and mainly asking about the participants experience in using Open Access sources. In order to hear their story, the researcher has prepared five general questions for the interviews. They are as follows:

1. Questions about their subjects

2. The way the participant search information for their lectures

3. Participant experience of using and finding Open Access sources

However, I noticed that I was very much relied on the questions that I have been prepared. When I have finished transcribing, I found there are some responses from the participants that I should have asked for more details. I have led the participants to answers the prepared questions, but it has showed that I still could not acquired meaty data. There were some responses that worth to be explored in more deep. The experience of conducting interviews has encouraged me to learn about how to conduct effective interviews.

A fundamental principle of in-depth interviewing is to listen. It is more about trying to hear the meaning of what participant is saying, understanding where there is a subtext that needs to be explored, and hearing the nuances in the participant's account. In keeping the nature of the interview, the follow-up questions could be determined by the interviewee's answer. However, as I have done several interviews, writing a list of thematic probe questions might help me in preparing the follow-up questions. I would also need to listen carefully to remember points that need to be followed up at a later stage. One response from an interviewee may trigger two or three points to probe. A swift decision needs to be taken about the immediate issue that needs to be followed up. From the interview transcripts I have written, it seems important to make a short note to return to the other issues raised, either 
once we have dealt with the immediate issue or later in the interview when we are dealing with a relevant topic.

\section{Conclusion}

The pilot study has been conducted and the researcher has step in to the main study by looking at lectures from other departments at the Humanities Faculty, Diponegoro University. At this stage, the researcher has transcribed and coded the interviews. This process of transcribing and coding the text will inform the researcher about the next step about what kind of key questions to be highlighted.

\section{References}

[1] S. Bernius, "The impact of open access on the management of scientific knowledge," Online Inf. Rev., vol. 34, no. 4, pp. 583-603, (2010).

[2] J. Willinsky, The Access Principle: The Case for Open Access to Research and Scholarship. Cambridge: MIT Press, (2006).

[3] C. Steele, "Open access in Australia: An odyssey of sorts?," Insights UKSG J., vol. 26, no. 3, pp. 282-289, (2013).

[4] M. Henty, "Ten major issues in providing a repository service in Australian universities," D-Lib Mag., vol. 13, no. 5-6, (2007).

[5] P. Gaulé and N. Maystre, "Getting cited: Does open access help?," Res. Policy, vol. 40, no. 10, pp. 1332-1338, (2011).

[6] T. Koler-Povh, P. Južnič, and G. Turk, "Impact of open access on citation of scholarly publications in the field of civil engineering," Scientometrics, vol. 98, no. 2, pp. 10331045, (2014).

[7] B. S. Jean, S. Y. Rieh, E. Yakel, and K. Markey, "Unheard voices: Institutional repository end-users," Coll. Res. Libr., vol. 72, no. 1, pp. 21-42, (2011).

[8] K. Valentine Stanton and C. Li Liew, "Open access theses in institutional repositories: an exploratory study of the perceptions of doctoral students," Inf. Res., vol. 16, no. 4, (2011).

[9] J. W. Cresswell, Research Design: Qualitative, Quantitative and Mixed Methods Approaches. Los Angeles: SAGE Publications, (2014).

[10] C. Marshall and G. B. Rossman, Designing qualitative research. Thousand Oaks: SAGE Publications, (2015).

[11] J. Chaudhuri and M. Thohira, "Usage of Open-Access Journals: Findings from Eleven Top Science and Medical Journals," Ser. Libr., vol. 58, no. 1-4, pp. 97-105, (2010).

[12] K. Williamson, V. Bernath, S. Wright, and J. Sullivan, "Research Students in the Electronic Age: Impacts of Changing Information Behavior on Information Literacy Needs," Comminfolit, vol. 1, no. 2, p. 47, (2008).

[13] R. Green and P. Macauley, "Doctoral students' engagement with information: An American-Australian perspective," Portal, vol. 7, no. 3, pp. 317-332, (2007).

[14] C. Bruce, Seven Faces of Information Literacy. Adelaide: AUSLIBPress, (1997).

[15] R. K. Yin, Qualitative Research from Start to Finish. New York: The Guilford Press, (2011). 